\title{
Comparison the Effect of Etomidate vs. Thiopentone on Left Ventricular Strain and Strain Rate at the Time of Anesthesia Induction in Patients Undergoing Elective Coronary Artery Bypass Surgery: A Randomized Double Blind Controlled Trial
}

\author{
Ummed Singh ${ }^{1}$ Minati Choudhury ${ }^{2}$ Arindum Choudhury ${ }^{2}$ Milind P. Hote ${ }^{3}$ Poonam Malhotra Kapoor ${ }^{2}$ \\ ${ }^{1}$ Department of Cardiac Surgical Intensive Care, All India Institute of \\ Medical Sciences, New Delhi \\ 2 Department of Cardiac Anaesthesia and Critical Care, All India \\ Institute of Medical Sciences, New Delhi \\ Address for correspondence Minati Choudhury, MD, Department of \\ Cardiac Anaesthesia and Critical Care, All India Institute of Medical \\ Sciences, New Delhi-110029, India \\ (e-mail: minatichoudhury2002@yahoo.co.in).
}

3 Department of Cardiothoracic and Vascular Surgery, All India Institute of Medical Sciences, New Delhi

J Card Crit Care 2021;5:201-207

\begin{abstract}
Keywords

- speckle tracking echocardiography

- strain

- strain rate

- etomidate

- thiopentone

Myocardial strain imaging with speckle tracking echocardiography (STE) is getting popularity because it does not depends on insonation angle and has shown good correlation with intraoperative and postoperative ventricular function in patients with coronary artery disease. The impact of thiopentone and etomidate induction on myocardial function was studied and compared on sixty patients undergoing elective coronary artery bypass grafting. Three loops for each views (apical 4 chamber, apical 2 chamber, and apical long axis ) were acquired at base line (T0) and 1 minute (T1) after induction for offline analysis. In Group T, significant increase in HR from the base line values $(67.8 \pm 13.8$ vs $79.2 \pm 15.6, p=0.001)$ occurred post induction, where as in Group $E$ it remain near to the base line $(71.7 \pm 8.3$ vs $70.1 \pm 8.9, p=0.345$ ). A reduction in mean arterial pressure (MAP) was noted in both the groups after the injection of the allocated drug. There was no significant difference in the index of contractility (ICON) (T0 vs T1: $48.7 \pm 10.6$ vs $47.0 \pm 11.7, p=0.120$ ) in Group $E$ where as in Group T there was a reduction in the ICON value (T0 vs T1: $45.0 \pm 10.7$ vs $41.0 \pm$ $8.4, \mathrm{p}=0.005)$. A similar picture was also noted in systemic vascular resistance index. A significant decrease in cardiac index $(\mathrm{Cl})$ was seen in Group $\mathrm{E}$ (T0 vs T1: $2.7 \pm 0.4$ vs $2.5 \pm 0.4$, $p=0.027)$, however it remain near to the base line in Group T. There occurred no changes in stroke index (SI) in Group E (T0 vs T1: $38.7 \pm 6$ vs $37.0 \pm 5.3, p=0.134$ ), where as a significant decrease was noted after injection of thiopental (T0 vs T1: $38.0 \pm 6.2$ vs $36.1 \pm 4.9, p=$ 0.049 ). A significant decline in cardiac performance index (CPI) was also recorded in Group $E$ (T0 vs T1: $0.57 \pm 0.15$ vs $0.52 \pm 0.12, p=0.032$ ), and not in Group T. There was decrease in left ventricular ejection fraction (LVEF) after the injection of both the drugs (Group E, T0 vs
\end{abstract}

DOI https://doi.org/ $10.1055 / \mathrm{s}-0042-1742618$. ISSN 2457-0206. (c) 2022. Official Publication of The Simulation Society (TSS), accredited by International Society of Cardiovascular Ultrasound (ISCU). All rights reserved.

This is an open access article published by Thieme under the terms of the Creative Commons Attribution-NonDerivative-NonCommercial-License, permitting copying and reproduction so long as the original work is given appropriate credit. Contents may not be used for commercial purposes, or adapted, remixed, transformed or built upon. (https://creativecommons.org/ licenses/by-nc-nd/4.0/)

Thieme Medical and Scientific Publishers Pvt. Ltd., A-12, 2nd Floor, Sector 2, Noida-201301 UP, India 
$\mathrm{T} 1: 57 \pm 3.7$ vs $54 \pm 3.7, \mathrm{p}=0.001$; and Group T, T0 vs T1: $57 \pm 3.7$ vs $54 \pm 3.7, p=0.001)$. In Group E, global longitudinal peak systolic strain (GLPSS) showed no change after the injection of the drug (T0 vs T1: $-13.2 \pm 2.2$ vs $-13.1 \pm 2.3, p=0.631$ ). However, a significant decrease in GLPSS (T0 vs T1: $-13.5 \pm 1.5$ vs $-10 \pm 1.8, \mathrm{p}=0.001$ ) after injection of thiopental. Longitudinal peak systolic strain rate (LPSSR) was significantly decreased in all echocardiographic views after the injection of respective drugs. However, the decrease in LPSSR was significantly less in Group E in comparison to Group T.

To conclude, STE provides accurate and reliable real time quantitative regional and global LV assessment. Use of thiopentone for anesthesia induction is associated with more profound impairment of LV function in comparison to etomidate as assessed by a decreased longitudinal peak systolic strain rate and global longitudinal peak systolic strain. Further studies are warranted to understand the exact clinical impact, which may influence the choice of intravenous induction agent based upon preoperative patient characteristics.

\section{Introduction}

The induction phase of anesthesia in adults starts with bringing wakeful patients into sleep like state, most commonly initiated by intravenous hypnotics such as thiopentone, etomidate or propofol. Effect of induction agent on myocardial function and henceforth on overall hemodynamics of the patient can have a significant impact on surgical outcome as there have been numerous documented reports of deterioration of patient vitals upon induction of anesthesia in critically ill cardiac patients. ${ }^{1,2}$ The direct impact of intravenous anesthetics has been largely overlooked because of the presumed short duration of action of these drugs and also lack of evaluation tools for detection of real-time impact of hypnotic agent on myocardial performance. It is, however, essential to have complete understanding of physiological response to prevent any inadvertent adverse sequelae.

Studies performed historically have used standard invasive hemodynamic parameters like heart rate (HR), mean arterial pressure (MAP), central venous pressure, systemic vascular resistance (SVR), stroke volume (SV), and cardiac index (CI) to indirectly evaluate the effect of drugs on the cardiovascular system. ${ }^{3,4}$ Plasma levels of various chemical biomarkers have also been used to quantitate the anesthetic agent induced myocardial insult under various clinical scenarios in patient undergoing cardiac surgery. ${ }^{5}$ Elevation of cardiac biomarkers may, however, not be solely attributed to insult caused by anesthetic agents in presence of a basal cardiac disease.

Intraoperative tissue Doppler imaging (TDI) is a helpful bedside tool to provide immediate insight into hemodynamic changes, loading conditions, and myocardial performance. However, only a few studies have used TDI to evaluate the impact of anesthetic agents on cardiac function. ${ }^{6}$ Speckle tracking echocardiography (STE) is considered superior to DTI since there is no dependence on insonation angle and has shown good correlation with intraoperative and postoperative left ventricular (LV) function in patients with ischemic heart disease. ${ }^{7}$

Global longitudinal strain and global longitudinal strain rate are novel STE-derived indices for noninvasive assess- ment of analysis of rotational myocardial motion and global LV function. Early validation studies with this method are suggestive of high sensitivity and specificity in the detection of both acute ischemic regional myocardial dysfunction and LV systolic dysfunction postmyocardial infarction. ${ }^{8-10}$

As it is pivotal to be aware of the direct myocardial compromising effects of induction anesthetic drugs in patients undergoing cardiac surgery, we conducted this trial with the belief that real-time intraoperative transthoracic two-dimensional STE can be used as a monitoring tool for the evaluation of myocardial function during the anesthesia induction phase.

This study was aimed at comparing the effect of etomidate and thiopentone on LV strain and strain rate at the time of anesthesia induction in patients undergoing myocardial revascularization surgery using STE. The primary outcomes that were assessed included longitudinal peak systolic strain (LPSS) and longitudinal peak systolic strain rate (LPSSR). The secondary outcome parameters included hemodynamic parameters derived using invasive arterial blood pressure and electrical cardiometry-based (ICON; Osypka Medical, Berlin, Germany) noninvasive cardiac output monitoring.

\section{Methodology}

After approval from ethical committee, we enrolled the patients scheduled for an elective coronary artery bypass grafting (CABG). Written and informed consent was obtained from each patient. Based on power calculations (type I error $<0.05$, type II error $<0.20$ ) of $20 \%$ tissue tracking changes and $25 \%$ standard deviations, this study was calculated to include 26 patients in each group. To compensate for missing data, 30 patients were included in each group. Patients between 45 and 70 years of age with normal LV function and acceptable transthoracic echocardiography (TTE) window posted for elective CABG surgery were included in the trial. Patients with persistent arrhythmias, associated structural heart disease, ejection fraction $<50 \%$, congestive cardiac failure on mechanical ventilation, intra-aortic balloon pump, redo surgery/emergency surgery, ongoing angina or acute myocardial infarction 
within the last 30 days, known adrenaline insufficiency, history of steroid use in the preceding 6 months, and those with severe systemic noncardiac disease other than diabetes and hypertension were excluded from the study.

Patients with poor echocardiographic window secondary to an emphysematous chest, any chest deformity or morbid obesity and patients with an anticipated difficult airway as assessed by Simplified Airway Risk Index score $>3$ were also excluded from the trial. ${ }^{11}$

The patients were randomized preoperatively by computer-generated random number table into two groups depending upon the induction agent they received (etomidate group E, $n=30$ or thiopentone group T, $n=30$ ). Patients were continued on all medical treatment (except angiotensinconverting enzyme inhibitors) till the morning of surgery. Antiplatelet drugs were stopped 5 days before surgery. All patients received premedication in the form of inj. morphine $0.1 \mathrm{mg} / \mathrm{kg}$ and inj. promethazine $25 \mathrm{mg}$ intramuscularly half hour before shifting to the operation theater. Routine monitoring done in all cases included electrocardiogram, pulse oximetry, electrical cardiometry-based (ICON; Osypka Medical, Berlin, Germany) noninvasive cardiac output monitoring, invasive arterial blood pressure, central venous pressure, neuromuscular monitoring using train of four response, and bispectral index (BIS, A-2000 XP, Aspect Medical Systems, Newton, Massachusetts, United States). Comprehensive TTE examination was done in all patients before induction of anesthesia and TTE loops were acquired and stored for offline analysis.

\section{Anesthesia Induction}

All patients were allowed to breathe spontaneously through a transparent facemask and breathing circuits with reservoir bag with $100 \%$ inspired oxygen at $10 \mathrm{~L} / \mathrm{min}$. The induction agent was prepared and administered by the anesthesiologist

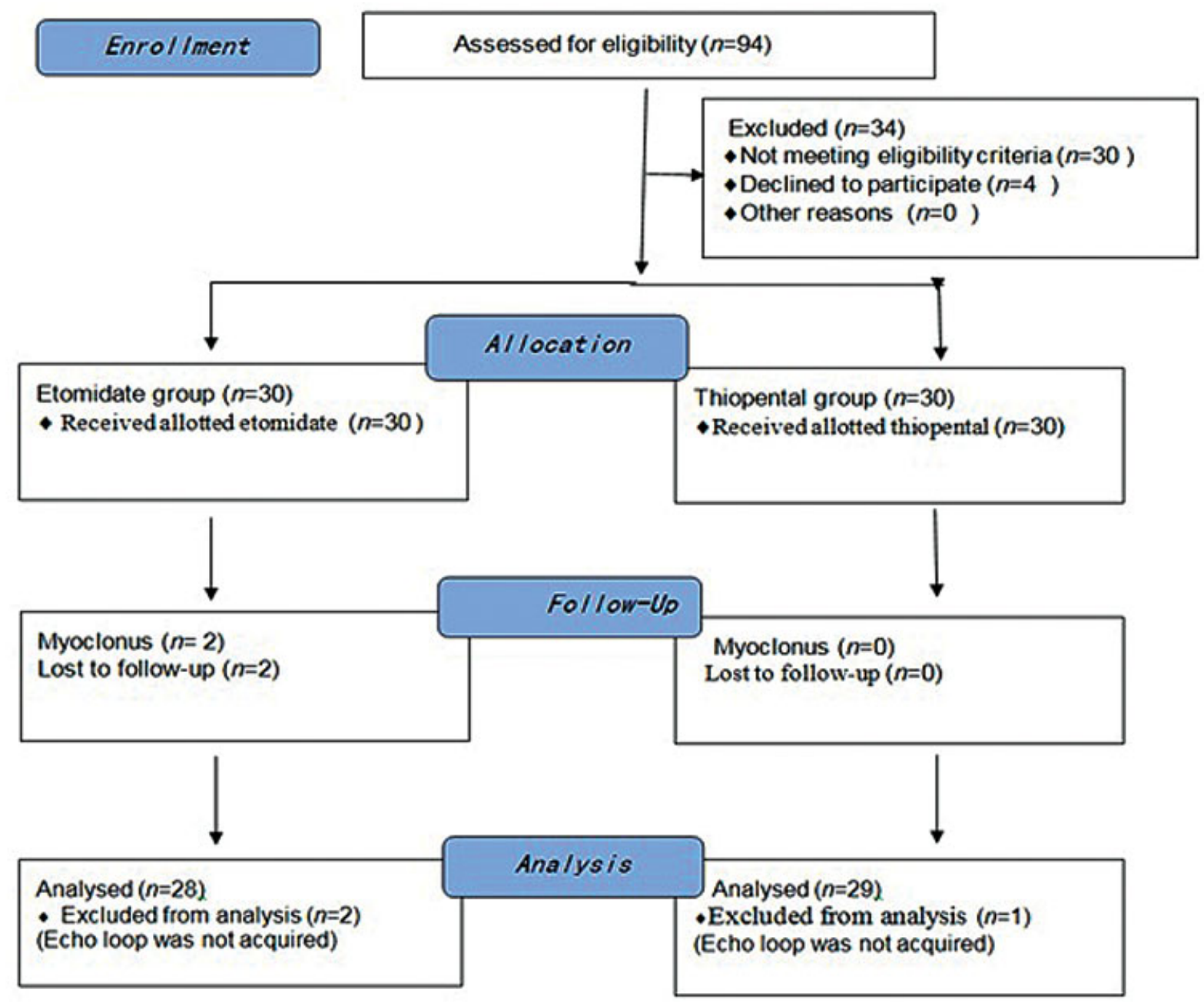

Fig. 1 Measurement of longitudinal peak systolic strain (LPSS) and longitudinal peak systolic strain rate (LPSSR) using the two-dimensional speckle tracking method in combination with automated function imaging. (A) In apical four-chamber view, the three-click method allows endocardial border tracing by clicking two basal points and one apical point during the end-systolic period. After automatic endocardial border detection and segmental allocation, the user can adjust the tracking borders manually. (B) Segmental LPSS was displayed on each segment of the image. A longitudinal

strain plot along and the cardiac cycle was displayed for each LV segment. (C) By clicking on strain rate bar, segmental LPSSR was displayed on each segment of the image. A longitudinal strain rate plot along and the cardiac cycle was displayed for each LV segment. (D) Repeating this process in apical two-chamber and long axis views, one can obtain global and segmental LPSS in a simple bull's-eye display. 
who was not a part of the study. Both the echocardiographer and hemodynamic data collector were also blinded about the drugs given. In group $\mathrm{E} 0.3 \mathrm{mg} / \mathrm{kg}$ of etomidate and in group $\mathrm{T}$ $4 \mathrm{mg} / \mathrm{kg}$ of thiopentone sodium was administered intravenous, respectively, gradually over a period of 15 seconds and ventilation was assisted. After 45 seconds of drug administration, when the loss of eyelash reflex was confirmed and a BIS value of $<60$ was noted, a second set of hemodynamic parameters (T1) was recorded and TTE loop was acquired and stored for offline analysis. Anesthesia was then supplemented with inj. fentanyl $3 \mu \mathrm{g} / \mathrm{kg}$, inj. midazolam $0.02 \mathrm{mg} / \mathrm{kg}$, and inj. rocuronium $0.8 \mathrm{mg} / \mathrm{kg}$. Complete induction was then confirmed by a lack of train of four responses, which was followed by tracheal intubation for the maintenance of anesthesia.

Hemodynamic assessment during the study was performed using electrical cardiometry (ICON; Osypka Medical, Berlin, Germany), a noninvasive method of cardiac output estimation. Cardiac output/index and other parameters (stroke index [SI], systemic vascular resistance index [SVRI], index of contractility [ICON], and cardiac performance index [CPI]) derived using electrical cardiometry have shown numerically comparable results to cardiac output derived using pulmonary artery catheterization in patients undergoing cardiac surgery.

\section{Transthoracic Echocardiography}

After positioning, the patient on operation table (supine with a slight left lateral tilt) serial TTE images were recorded using a portable IE33 XMATRIX echocardiography system and S5-1 transducer. Loops were acquired at baseline (T0) and $1 \mathrm{~min}$ (T1) after induction agent injection, along with hemodynamic and electrical cardiometry recording at the same time frames. Three loops were acquired for each of the following views (apical four chamber, apical two chamber, apical long axis) and saved for offline speckle tracking analysis.

Offline Analysis: Offline speckle tracking imaging analysis was done by an experienced sonographer who was unaware of the drug assigned, with advanced tissue motion quantification (TMQ) software on the QLAB 7.0 workstation. Once the guidance points are placed manually (one point at the apex and two points at the base of LV), the software creates regions of interest automatically by marking the outline of the endocardium in the TMQ mode, which can then be manually adjusted. The software calculated predetermined functional parameters automatically. In the apical long-axis view, the software automatically determined aortic valve closure time. The LV long-axis view included the basal, mid ventricular, apical sections, and LV apex. After all tracking were performed, the software computed the LPSS, recorded the systolic strain peak of all curves with the start of the electrocardiographic $\mathrm{R}$ wave as the starting point of LV systole and the R-R interval as one cardiac cycle, and then separately calculated the global longitudinal peak systolic strain (GLPSS). The software also computed LPSSR, recorded systolic strain rate curves for all segment, and a curve showing average for all segments, with the start of the electrocardiographic $\mathrm{R}$ wave as the starting point of $\mathrm{LV}$ systole (-Fig. 1). Left ventricular ejection fraction (LVEF) was calculated with Simpson's method.

The following CONSERT chart represents details about allocation of the patients.

\section{Statistical Analysis}

Data analysis was performed using Stata 12.0 (Statacorp Lp, Texas, United States) software. Data were presented as number (\%) or mean \pm standard deviation as appropriate. Baseline categorical and continuous variables were compared between the groups using chi-square test and $t$-test for independent samples, respectively. The primary outcomes and secondary outcomes were compared between the groups using Student's $t$-test for independent samples and within the groups using paired " $\mathrm{t}$ " test. The results were reported as mean differences (95\% confidence interval). The $p$-value less than 0.05 was considered as statistically significant.

\section{Results}

Two patients from group $\mathrm{E}$ (had myoclonus) and one from group $\mathrm{T}$ (poor echocardiographic window) were not included in final analysis.

Table 1 Patient demographics, data presented as mean \pm SD or number percentage. The value in parenthesis implies number percentage

\begin{tabular}{|c|c|c|c|}
\hline Variables & $\begin{array}{l}\text { Group E, } \\
N=28\end{array}$ & $\begin{array}{l}\text { Group T, } \\
N=29\end{array}$ & $p$-Value \\
\hline Age $(y)$ & $55.8 \pm 8.3$ & $57.8 \pm 7.4$ & 0.340 \\
\hline \multicolumn{4}{|l|}{ Sex } \\
\hline M & $24(80.0)$ & $24(80.0)$ & \multirow[t]{2}{*}{0.999} \\
\hline $\mathrm{F}$ & $06(20.0)$ & $06(20.0)$ & \\
\hline BMI $\left(\mathrm{kg} / \mathrm{m}^{2}\right)$ & $25 \pm 2.5$ & $25.4 \pm 2.9$ & 0.538 \\
\hline $\mathrm{BSA}\left(\mathrm{m}^{2}\right)$ & $1.7 \pm 0.1$ & $1.7 \pm 0.2$ & 0.596 \\
\hline HTN & $12(40.0)$ & $13(43.0)$ & 0.793 \\
\hline DM & $13(43.0)$ & $12(40.0)$ & 0.793 \\
\hline Smoking & $18(60.0)$ & $17(56.6)$ & 0.793 \\
\hline B-blocker & $26(86.6)$ & $25(83.3)$ & 0.999 \\
\hline $\mathrm{CCB}$ & $8(26.6)$ & $10(33.3)$ & 0.573 \\
\hline Nitrates & $28(93.3)$ & $28(93.3)$ & 0.999 \\
\hline Statins & $27(90.0)$ & $28(93.3)$ & 0.640 \\
\hline ACE inhibitor & $19(63.3)$ & $20(66.6)$ & 0.787 \\
\hline Ranolazine & $15(44.1)$ & $19(63.3)$ & 0.297 \\
\hline Nicorandil & $10(33.3)$ & $12(40.0)$ & 0.592 \\
\hline $\mathrm{OHD}$ & $12(40.0)$ & $12(40.0)$ & 0.999 \\
\hline
\end{tabular}

Abbreviations: BMI, body mass index; BSA, body surface area; $C C B$, calcium channel blocker; DM, diabetes mellitus; HTN, hypertension; $\mathrm{OHD}$, oral hypoglycemic drug; SD, standard deviation.

Values expressed as mean \pm standard deviation or as $\mathrm{N}$; number (percentage). $p$-Value $<0.05$ considered as statistically significant. 
Table 2 Hemodynamic variables; data presented as mean \pm SD

\begin{tabular}{|c|c|c|c|c|}
\hline Variable & Group $\mathrm{E}, \mathrm{N}=28$ & Group $\mathrm{T}, N=29$ & Difference ( $95 \%$ confidence interval) & p-Value \\
\hline $\begin{array}{l}\text { HR (T0) } \\
(\mathrm{T} 1) \\
p \text {-Value }\end{array}$ & $\begin{array}{l}71.7 \pm 8.3 \\
70.1 \pm 8.9 \\
0.345\end{array}$ & $\begin{array}{l}67.8 \pm 13.8 \\
79.2 \pm 15.6 \\
0.001\end{array}$ & $\begin{array}{l}3.9(-2.0,9.8) \\
-9.1(-15.6,-2.5)\end{array}$ & $\begin{array}{l}0.192 \\
0.007\end{array}$ \\
\hline $\begin{array}{l}\text { SBP (T0) } \\
(\mathrm{T} 1) \\
p \text {-Value }\end{array}$ & $\begin{array}{l}155.8 \pm 18.8 \\
134.6 \pm 22.7 \\
0.001\end{array}$ & $\begin{array}{l}153.5 \pm 19.7 \\
129.0 \pm 21.6 \\
0.001\end{array}$ & $\begin{array}{l}2.3(-7.6,12.3) \\
5.6(-5.9,17.0)\end{array}$ & $\begin{array}{l}0.641 \\
0.335\end{array}$ \\
\hline $\begin{array}{l}\mathrm{DBP}(\mathrm{T} 0) \\
(\mathrm{T} 1) \\
p \text {-Value }\end{array}$ & $\begin{array}{l}80.2 \pm 10.5 \\
71.3 \pm 10.17 \\
0.001\end{array}$ & $\begin{array}{l}77.7 \pm 13.2 \\
68.1 \pm 14.1 \\
0.001\end{array}$ & $\begin{array}{l}2.5(-3.6,8.6) \\
3.2(-3.1,9.6)\end{array}$ & $\begin{array}{l}0.422 \\
0.309\end{array}$ \\
\hline $\begin{array}{l}\text { MAP (T0) } \\
(\mathrm{T} 1) \\
p \text {-Value }\end{array}$ & $\begin{array}{l}105.6 \pm 12.4 \\
91.9 \pm 12.3 \\
0.001\end{array}$ & $\begin{array}{l}102.4 \pm 11.6 \\
87.8 \pm 14.6 \\
0.001\end{array}$ & $\begin{array}{l}3.2(-3.1,9.5) \\
4.0(-3.0,11.1)\end{array}$ & $\begin{array}{l}0.315 \\
0.256\end{array}$ \\
\hline $\begin{array}{l}\text { SPO2 (T0) } \\
\text { (T1) } \\
p \text {-Value }\end{array}$ & $\begin{array}{l}98.5 \pm 1.5 \\
100 \pm 0 \\
0.001\end{array}$ & $\begin{array}{l}98.2 \pm 2.4 \\
99.9 \pm 0.1 \\
0.004\end{array}$ & $\begin{array}{l}0.3(-0.6,1.4) \\
0.03(-0.03,0.1)\end{array}$ & $\begin{array}{l}0.486 \\
0.321\end{array}$ \\
\hline $\begin{array}{l}\text { BIS (T0) } \\
(\mathrm{T} 1) \\
p \text {-Value }\end{array}$ & $\begin{array}{l}97.5 \pm 0.8 \\
54.3 \pm 4.4 \\
0.001\end{array}$ & $\begin{array}{l}97.4 \pm 1.7 \\
55.3 \pm 7.7 \\
0.001\end{array}$ & $\begin{array}{l}0.2(-0.5,0.8) \\
-0.9(-4.2,2.3)\end{array}$ & $\begin{array}{l}0.645 \\
0.557\end{array}$ \\
\hline $\begin{array}{l}\text { ICON (T0) } \\
(\mathrm{T} 1) \\
p \text {-Value }\end{array}$ & $\begin{array}{l}48.7 \pm 10.6 \\
47.0 \pm 11.7 \\
0.120\end{array}$ & $\begin{array}{l}45.0 \pm 10.7 \\
41.0 \pm 8.4 \\
0.005\end{array}$ & $\begin{array}{l}3.7(-1.8,9.2) \\
5.4(-0.2,10.8)\end{array}$ & $\begin{array}{l}0.189 \\
0.056\end{array}$ \\
\hline $\begin{array}{l}\text { CPI (T0) } \\
(\mathrm{T} 1) \\
p \text {-Value }\end{array}$ & $\begin{array}{l}0.57 \pm 0.15 \\
0.52 \pm 0.12 \\
0.032\end{array}$ & $\begin{array}{l}0.59 \pm 0.20 \\
0.62 \pm 0.17 \\
0.330\end{array}$ & $\begin{array}{l}0.05(0.004,0.17) \\
-0.02(-0.07,0.02)\end{array}$ & $\begin{array}{l}0.663 \\
0.012\end{array}$ \\
\hline $\begin{array}{l}\text { SVRI (T0) } \\
(\mathrm{T} 1) \\
p \text {-Value }\end{array}$ & $\begin{array}{l}2864.7 \pm 664.23029 .3 \pm 594.7 \\
00.119\end{array}$ & $\begin{array}{l}3096 \pm 610.8 \\
2746.4 \pm 663.6 \\
0.002\end{array}$ & $\begin{array}{l}-331.5(-661.3,-1.7) \\
282.9(-54.2,620.1)\end{array}$ & $\begin{array}{l}0.058 \\
0.098\end{array}$ \\
\hline $\begin{array}{l}\mathrm{Cl}(\mathrm{T} 0) \\
(\mathrm{T} 1) \\
p \text {-Value }\end{array}$ & $\begin{array}{l}2.7 \pm 0.4 \\
2.5 \pm 0.3 \\
0.027\end{array}$ & $\begin{array}{l}3.0 \pm 00.78 \\
2.9 \pm 00.59 \\
0.728\end{array}$ & $\begin{array}{l}-0.2(-0.6,0.1) \\
-0.4(-0.7,-0.2)\end{array}$ & $\begin{array}{l}0.164 \\
0.003\end{array}$ \\
\hline $\begin{array}{l}\text { SI (T0) } \\
(\mathrm{T} 1) \\
p \text {-Value }\end{array}$ & $\begin{array}{l}38.7 \pm 6.0 \\
37.0 \pm 5.3 \\
0.134\end{array}$ & $\begin{array}{l}38.0 \pm 6.2 \\
36.1 \pm 4.9 \\
0.049\end{array}$ & $\begin{array}{l}0.7(-2.4,3.8) \\
0.9(-1.8,3.6)\end{array}$ & $\begin{array}{l}0.666 \\
0.515\end{array}$ \\
\hline
\end{tabular}

Abbreviations: BIS, bispectral index; $\mathrm{Cl}$, cardiac index; CPI, cardiac performance index; DBP, diastolic blood pressure; HR, heart rate; ICON, index of contractility; MAP, mean arterial pressure; SBP, systolic blood pressure; SD, standard deviation; SI, stroke index; SVRI, systemic vascular resistance index.

The baseline demographic data showed no significant difference between the two groups (-Table 1). - Table 2 demonstrates baseline hemodynamic parameters (T0) and the changes that occurred after the injection of etomidate or thiopental (T1).

In patients treated with etomidate, no significant change in HR was noted $(71.7 \pm 8.3$ vs. $70.1 \pm 8.9, p=0.345)$. Injection of thiopental, however, caused significant increase in HR from the baseline values $(67.8 \pm 13.8$ vs. $79.2 \pm 15.6$, $p=0.001)$. A reduction in MAP was noted in both the groups after the injection of the allocated drug (T0 vs. T1: $105.6 \pm 12.4$ vs. $91.9 \pm 12.3, p=0.001$ ) and (T0 vs. T1: $102.4 \pm 11.6$ vs. $87.8 \pm 14.6, p=0.001$ ) in group $\mathrm{E}$ and group $\mathrm{T}$, respectively. There was no significant difference in the ICON (T0 vs. T1: $48.7 \pm 10.6$ vs. $47.0 \pm 11.7, p=0.120$ ) after injection of etomidate. The injection of thiopental was, however, associated with a significant reduction in the ICON value (T0 vs. T1: $45.0 \pm 10.7$ vs. $41.0 \pm 8.4, p=0.005$ ). Even though the SVRI was maintained after the injection of etomidate, thiopental caused SVRI to decrease significantly (T0 vs. T1: $3196 \pm 610.8$ vs. $2746.4 \pm 663.6, p=0.002$ ). In the etomidate group, CI decreased significantly (T0 vs. T1: $2.7 \pm 0.4$ vs. $2.5 \pm 0.4, p=0.027$ ) after injection of etomidate; however, no significant changes in $\mathrm{CI}$ were seen after thiopental injection (T0 vs. T1: $3 \pm 0.78$ vs. $2.9 \pm 0.59, p=0.728$ ). There occurred no changes in SI after the injection of etomidate (T0 vs. T1: $38.7 \pm 6$ vs. $37.0 \pm 5.3, p=0.134$ ) but significant decrease was noted after injection of thiopental (T0 vs. $\mathrm{T} 1: 38.0 \pm 6.2$ vs. $36.1 \pm 4.9, p=0.049$ ). A significant decline in CPI was also recorded after injection of etomidate (T0 vs. T1: $0.57 \pm 0.15$ vs. $0.52 \pm 0.12, p=0.032$ ); increase in CPI (T0 vs. T1: $0.59 \pm 0.2$ vs. $0.62 \pm 0.17, p=0.330$ ) after injection of thiopental was, however, not statistically significant.

Baseline echocardiographic parameters ejection fraction, LPSS, and strain rate were similar in both the groups (-Table 3). LVEF decreased significantly after the injection of etomidate (T0 vs. T1: $57 \pm 3.7$ vs. $54 \pm 3.7, p=0.001$ ) and 
Table 3 Echocardiography parameters; data presented as mean \pm SD

\begin{tabular}{|c|c|c|c|c|}
\hline Variable & Group E $(n=28)$ & $\begin{array}{l}\text { Group T } \\
(n=29)\end{array}$ & Difference $(95 \% \mathrm{Cl})$ & $p$-Value \\
\hline $\begin{array}{l}\text { LVEF (T0) } \\
\text { (T1) } \\
p \text {-Value }\end{array}$ & $\begin{array}{l}57 \pm 3.7 \\
54 \pm 3.7 \\
0.001\end{array}$ & $\begin{array}{l}56 \pm 1.2 \\
54 \pm 2.3 \\
0.001\end{array}$ & $\begin{array}{l}1(-4.5,2.4) \\
0.0(-1.63,1.63)\end{array}$ & $\begin{array}{l}0.17 \\
1.00\end{array}$ \\
\hline $\begin{array}{l}\text { LPSS AP4C (T0) } \\
\text { (T1) } \\
p \text {-Value }\end{array}$ & $\begin{array}{l}-13.8 \pm 2.5 \\
-13.7 \pm 2.6 \\
0.812\end{array}$ & $\begin{array}{l}-14 \pm 1.5 \\
-10.8 \pm 2.1 \\
0.001\end{array}$ & $\begin{array}{l}0.2(-0.8,1.2) \\
-2.8(-4.1,-1.6)\end{array}$ & $\begin{array}{l}0.713 \\
0.001\end{array}$ \\
\hline $\begin{array}{l}\text { LPSS AP2C (T0) } \\
\text { (T1) } \\
p \text {-Value }\end{array}$ & $\begin{array}{l}-12.9 \pm 2.4 \\
-13.1 \pm 2.7 \\
0.801\end{array}$ & $\begin{array}{l}-13.3 \pm 1.9 \\
-10.6 \pm 2.5 \\
0.001\end{array}$ & $\begin{array}{l}0.4(-0.8,1.5) \\
-2.5(-3.9,-1.2)\end{array}$ & $\begin{array}{l}0.521 \\
0.005\end{array}$ \\
\hline $\begin{array}{l}\text { LPSS APLX (T0) } \\
(\mathrm{T} 1) \\
p \text {-Value }\end{array}$ & $\begin{array}{l}-12.9 \pm 2.5 \\
-13 \pm 2.6 \\
0.999\end{array}$ & $\begin{array}{l}-13.5 \pm 1.7 \\
-10.6 \pm 2.3 \\
0.001\end{array}$ & $\begin{array}{l}0.6(-0.5,1.7) \\
-2.5(-3.7,-1.2)\end{array}$ & $\begin{array}{l}0.268 \\
0.003\end{array}$ \\
\hline $\begin{array}{l}\text { GLPSS (T0) } \\
(\mathrm{T} 1) \\
p \text {-Value }\end{array}$ & $\begin{array}{l}-13.2 \pm 2.2 \\
-13.1 \pm 2.3 \\
0.631\end{array}$ & $\begin{array}{l}-13.5 \pm 1.5 \\
-10 \pm 1.8 \\
0.001\end{array}$ & $\begin{array}{l}0.3(-0.6,1.3) \\
-2.4(-3.5,-1.4)\end{array}$ & $\begin{array}{l}0.501 \\
0.001\end{array}$ \\
\hline $\begin{array}{l}\text { LPSSR AP4C } \\
\text { (T0) } \\
\text { (T1) } \\
p \text {-Value }\end{array}$ & $\begin{array}{l}-0.71 \pm 0.10 \\
-0.48 \pm 0.08 \\
0.001\end{array}$ & $\begin{array}{l}-0.73 \pm 0.09 \\
-0.38 \pm 0.05 \\
0.001\end{array}$ & $\begin{array}{l}0.02(-0.03,0.07) \\
-0.09(-0.1,-0.06)\end{array}$ & $\begin{array}{l}0.461 \\
0.001\end{array}$ \\
\hline $\begin{array}{l}\text { LPSSR AP2C } \\
(\mathrm{T} 0) \\
(\mathrm{T} 1) \\
p \text {-Value }\end{array}$ & $\begin{array}{l}-0.70 \pm 0.09 \\
-0.52 \pm 0.06 \\
0.001\end{array}$ & $\begin{array}{l}-0.71 \pm 0.09 \\
-0.39 \pm 0.04 \\
0.001\end{array}$ & $\begin{array}{l}0.01(-0.04,0.06) \\
-0.1(-0.2,-0.1)\end{array}$ & $\begin{array}{l}0.683 \\
0.001\end{array}$ \\
\hline $\begin{array}{l}\text { LPSSR APLAX } \\
\text { (T0) } \\
\text { (T1) } \\
p \text {-Value }\end{array}$ & $\begin{array}{l}-0.70 \pm 0.11 \\
-0.53 \pm 0.09 \\
0.001\end{array}$ & $\begin{array}{l}-0.72 \pm 0.06 \\
-0.39 \pm 0.04 \\
0.001\end{array}$ & $\begin{array}{l}0.01(-0.03,0.06) \\
-0.1(-0.2,-0.1)\end{array}$ & $\begin{array}{l}0.489 \\
0.001\end{array}$ \\
\hline
\end{tabular}

Abbreviations: AP2C, apical 2 chamber; AP4C, apical 4 chamber; APLAX, apical long axis; Cl, confidence interval; GLPSS, global longitudinal peak systolic strain; LPSS, longitudinal peak systolic strain; LPSSR, longitudinal peak systolic strain rate; LVEF, left ventricular ejection fraction; SD, standard deviation.

All values expressed as mean \pm standard deviation. $p$-Values $<0.05$ considered as statistically significant.

thiopental (T0 vs. T1: $57 \pm 3.7$ vs. $54 \pm 3.7, p=0.001$ ). In the etomidate group, GLPSS (T0 vs. T1: $-13.2 \pm 2.2$ vs. $-13.1 \pm 2.3, p=0.631$ ) showed no change after the injection of the drug. There was, however, a significant decrease in GLPSS (T0 vs. T1: $-13.5 \pm 1.5$ vs. $-10 \pm 1.8, p=0.001$ ) after injection of thiopental. LPSSR was significantly decreased in all echocardiographic views after the injection of respective drugs. However, the decrease in LPSSR was significantly less with the injection of etomidate in comparison to thiopental.

\section{Discussion}

Outcome after coronary artery surgery depends upon multitude of factors, and choice of appropriate induction agent is one of them. ${ }^{12}$ Among the wide variety of available anesthesia induction drugs, thiopentone and etomidate are most frequently used agents. Safety and efficacy of individual drug as well as their combination has been studied previously in various clinical trials, on patients undergoing CABG surgery. ${ }^{1,13-15}$ Although all the available drugs can be used for anesthesia induction in CABG surgery, one agent is preferred above another according to LV function and clinical status of the individual patient.
The present study was designed to evaluate and compare the direct impact on myocardium with STE, by the two most commonly used (thiopentone and etomidate) anesthesia induction agents for CABG surgery. We observed that clinical dose of etomidate or thiopental for anesthesia induction commonly revealed a significant decrease in LVEF and LPSSR. GLPSS remained unaltered with the injection of etomidate $(p=0.631)$, but decreased significantly after thiopental injection $(p=0.001)$.

STE provides real-time quantitative regional and global LV assessment and has been validated above past 15 years. ${ }^{16,17}$ Strain rate calculated by STE is more accurate than strain as its independence of preload. ${ }^{18,19}$ In our study, decline in LPSSR was observed in both the groups, which suggests both drugs depress myocardial contractility, but the decrease in strain rate was more profound in thiopental group $(p=0.001)$.

The results of this study are coherent with that conducted by Gauss et al who investigated the effect of etomidate, thiopentone, and propofol on myocardial function with combination of M-mode echocardiography and invasive arterial pressure measurement. ${ }^{20}$ They calculated end-systolic quotient (ESQ) = systolic pressure/end-systolic diameter and fractional shortening, before and $1 \mathrm{~min}$ after injection 
of respective drug. ESQ was used as a measure of inotropy, which remained unchanged after etomidate injection. Thiopentone and propofol exhibited negative inotropic effect on myocardium. In our study, thiopentone caused a decrease in EF, GLPSS, and LPSS.

A significant decrease in electrical cardiometry derived ICON value as well as GLPSS at the same time suggesting a drug dependent impact on myocardial contractility after thiopental injection during anesthesia induction. No significant change in $\mathrm{Cl}$ can be explained by a compensatory increase in HR and decrease in SVRI. SI remained unchanged after etomidate injection suggestive of relatively preserved myocardial contractility, while significant decrease in SI, despite decreased SVRI after thiopental injection again, indicates myocardial depression effect of thiopental.

The limitation of this study is that it included patients with normal LV systolic function and parameter suggestive of diastolic dysfunction was not assessed. The other drawback is that only longitudinal strain and strain rate were calculated, radial and circumferential strains were not calculated. The calculation of radial and circumferential strain requires parasternal short axis views for which extensive patient positioning and probe manipulation are required, which were not feasible at the time of induction. Parameters suggestive of myocardial oxygen demand and oxygen consumption at the time of induction were also not included in our study.

To conclude, STE provides accurate and reliable real-time quantitative regional and global LV assessment. Use of thiopentone for anesthesia induction is associated with more profound impairment of LV function in comparison to etomidate as assessed by a decreased LPSSR and global LPSS. Further studies are warranted to understand the exact clinical impact, which may influence the choice of intravenous induction agent based upon preoperative patient characteristics.

\section{References}

1 Singh R, Choudhury M, Kapoor PM, Kiran U. A randomized trial of anesthetic induction agents in patients with coronary artery disease and left ventricular dysfunction. Ann Card Anaesth 2010;13(03):217-223

2 Yang HS, Kim TY, Bang S, et al. Comparison of the impact of the anesthesia induction using thiopental and propofol on cardiac function for non-cardiac surgery. J Cardiovasc Ultrasound 2014; 22(02):58-64

3 Kling D, Laubenthal H, Börner U, Boldt J, Hempelmann G. [Comparative hemodynamic study of anesthesia induction with propofol (Diprivan), thiopental, methohexital, etomidate and midazolam in patients with coronary disease]. Anaesthesist 1987;36(10):541-547

4 Harris CE, Murray AM, Anderson JM, Grounds RM, Morgan M. Effects of thiopentone, etomidate and propofol on the haemody- namic response to tracheal intubation. Anaesthesia 1988;43 (Suppl):32-36

5 Kahn N, Riedlinger J, Roessler M, et al. Biomarker determinations altered by anesthesia induction. Eur Respir J 2012;40:761

6 Yang HS, Song BG, Kim JY, Kim SN, Kim TY. Impact of propofol anesthesia induction on cardiac function in low-risk patients as measured by intraoperative Doppler tissue imaging. J Am Soc Echocardiogr 2013;26(07):727-735

7 Yin ZY, Li XF, Tu YF, Dong DD, Zhao DL, Shen B. Speckle-tracking imaging to monitor myocardial function after coronary artery bypass graft surgery. J Ultrasound Med 2013;32(11):1951-1956

8 Reisner SA, Lysyansky P, Agmon Y, Mutlak D, Lessick J, Friedman Z. Global longitudinal strain: a novel index of left ventricular systolic function. J Am Soc Echocardiogr 2004;17(06):630-633

9 Winter R, Jussila R, Nowak J, Brodin LA. Speckle tracking echocardiography is a sensitive tool for the detection of myocardial ischemia: a pilot study from the catheterization laboratory during percutaneous coronary intervention. J Am Soc Echocardiogr 2007;20(08):974-981

10 Kukucka M, Nasseri B, Tscherkaschin A, Mladenow A, Kuppe H, Habazettl $\mathrm{H}$. The feasibility of speckle tracking for intraoperative assessment of regional myocardial function by transesophageal echocardiography. J Cardiothorac Vasc Anesth 2009;23(04): 462-467

11 el-Ganzouri AR, McCarthy RJ, Tuman KJ, Tanck EN, Ivankovich AD. Preoperative airway assessment: predictive value of a multivariate risk index. Anesth Analg 1996;82(06):1197-1204

12 Tuman KJ, McCarthy RJ, Spiess BD, DaValle M, Dabir R, Ivankovich AD. Does choice of anesthetic agent significantly affect outcome after coronary artery surgery? Anesthesiology 1989;70(02):189-198

13 Habibi MR, Baradari AG, Soleimani A, et al. Hemodynamic responses to etomidate versus ketamine-thiopental sodium combination for anesthetic induction in coronary artery bypass graft surgery patients with low ejection fraction: a double-blind, randomized, clinical trial. J Clin Diagn Res 2014;8(10):GC01-GC05

14 Haessler R, Madler C, Klasing S, Schwender D, Peter K. Propofol/fentanyl versus etomidate/fentanyl for the induction of anesthesia in patients with aortic insufficiency and coronary artery disease. J Cardiothorac Vasc Anesth 1992;6(02):173-180

15 Basagan-Mogol E, Goren S, Korfali G, Turker G, Kaya FN. Induction of anesthesia in coronary artery bypass graft surgery: the hemodynamic and analgesic effects of ketamine. Clinics (São Paulo) 2010;65(02):133-138

16 Feigenbaum H, Mastouri R, Sawada S. A practical approach to using strain echocardiography to evaluate the left ventricle. Circ J 2012;76(07):1550-1555

17 Hoit BD. Strain and strain rate echocardiography and coronary artery disease. Circ Cardiovasc Imaging 2011;4(02): 179-190

18 Choi JO, Shin DH, Cho SW, et al. Effect of preload on left ventricular longitudinal strain by 2D speckle tracking. Echocardiography 2008;25(08):873-879

19 Marwick TH, Marwick TH. Measurement of strain and strain rate by echocardiography: ready for prime time? J Am Coll Cardiol 2006;47(07):1313-1327

20 Gauss A, Heinrich H, Wilder-Smith OH. Echocardiographic assessment of the haemodynamic effects of propofol: a comparison with etomidate and thiopentone. Anaesthesia 1991;46(02):99-105 